Original Research Paper

\title{
Ecosphere Protection through Green Energy
}

\author{
${ }^{1}$ Relly Victoria V. Petrescu, ${ }^{2}$ Raffaella Aversa, ${ }^{2}$ Antonio Apicella, \\ ${ }^{3}$ Shuhui Li and ${ }^{1}$ Florian Ion T. Petrescu \\ ${ }^{1}$ Bucharest Polytechnic University, Bucharest, Romania \\ ${ }^{2}$ Advanced Materials Lab, Second University of Naples, Naples, Italy \\ ${ }^{3}$ University of Alabama, United States
}

\author{
Article history \\ Received: 10-02-2016 \\ Revised: 16-10-2016 \\ Accepted: 17-10-2016 \\ Corresponding Author: \\ Florian Ion T. Petrescu \\ Department of Theory of \\ Mechanisms and Robots, \\ Bucharest Polytechnic \\ University, Bucharest, Romania \\ Email: petrescuflorian@yahoo.com
}

\section{Introduction}

The sustainability concern (the balance in
economic growth, social well-being and
environmental protection) resides at the center of any
industrial research development and will be the basis
of our future development of our Technosphere,
where techno diversity spreads its effect into the
biosphere (Barrett and Odum, 2000; Mohsin, 2015;
Sepúlveda, 2015; Pisselo et al., 2015).
In particular, environmental challenges, such as
climate change and resource scarcity, are the sources of
both constraints and opportunities for new technological
developments (Apicella et al., 2010; Colvin, 2004;
de Silva et al., 2009; Kaebernick et al., 2002).
Sustainability, which is a theme in a long future in the

\begin{abstract}
A systemic approach, comprising all research and development activities that support the expansion of eco-efficient industrial and social systems fulfilling market and social-cultural constrains, is required to accomplish the challenge for competitiveness and sustainability along with an increasingly dynamic and complex global scientific, industrial and cultural scenarios. Ecosphere protection through the implementation of green energy is becoming a daily technological reality. Especially in recent years, various sources of green energy have been introduced in our Technosphere and Valuesphere. The process, which has began with difficulty but finally resulted in the acceleration and implementation of new green energy technologies, is still impaired by major emerging limitations. The most worldwide experienced difficult obstacle was the unpredictable and fluctuating green energy production. This study proposes some solutions designed to solve this unpleasant aspect of inconstant production of green energy. The basic idea refers to the construction of specially designed hydroelectric plant that represents a true energy buffer. A hydroelectric old (adequately equipped) or a new one built according to this principle, can become a true buffer energetic, able to take energy generated by the turbines at full capacity (energy otherwise lost by unable to be stored or taken over by the national network) and a national system restore when green energy sources produce shorten.
\end{abstract}

Keywords: Environmental Protection, Ecosphere, Technosphere, Valuesphere, Green Energy, Renewable Energy, Sustainable Energy, Wind Power, Hydropower, Pumped-Storage world, is particularly critical in Europe emerging Countries due to their rapid and uncontrolled industrial growth.

A more rational use of energy associated to the adoption of greener sources and control during production will improve our Valuesphere, which is the scientific environment accounting for the ecological issues while preserving occupation and welfare (Hofstetter et al., 2000).

Our planet is daily producing increasing amounts of Carbon dioxide and other gases that are released in the atmosphere and that are able to last for hundred years. This growing content of gases increases the warming of our planet. An answer to global warming is to exchange and retrofit current technologies with alternatives that have comparable or even higher performance, while do not releasing global warming gases. 
By 2050, a minimum of one third of the global energy has to be developed from sun, wind and other "clean" renewable resources. Even oil companies such as "British Oil" and "Royal Dutch Shell", which are two of the world's largest oil corporations, agree on this energy production target.

Global climate changes, the increment of planet population and fuel depletion, require that, in the next future, renewable energy should play an even more relevant role than it is achieving now (Pineda and Bock, 2016; Barone et al., 2015).

All these new energies need to avoid unpleasant consequences such as those, for example, associated to the use of fossil or nuclear fuels. Valid feasible alternative energy sources need to be renewable and "free". In addition, the production of these alternative energies should present decreased carbon dioxide emissions compared to the conventional ones. These may include: Biomass Energy, Wind Energy, Solar Energy, Geothermal Energy, Hydroelectric Energy, Tidal Energy, Wave Energy, (Petrescu and Petrescu, 2011; 2012).

Due to the lack of sources and the still high costs of the production of these alternatives, energy from nuclear fission has been then fundamentally a necessity and a hardly tolerated evil. Despite all related risks, the use of this type of energy has been able to manage the increasing critical energy crisis of humanity until new advanced technologies will allow us to gather the transition to alternative cleaner energies.

Once implemented, the nuclear fusion will be the most powerful energy source for mankind (Petrescu and Petrescu, 2014). Despite great advances have been made in this direction, nuclear fusion power plants have not yet realized.

Nuclear fusion power could not yet be made, but its season is fast approaching. Because it is not known when it could be operative for large production, it should be required to equip us in advance with green energy farms. Presently, the most numerous ones, since easy to built and run, are the wind and the solar farms (Ramenah and Tanougast, 2016). However, a reliability technical problem is to have time spans when they produce less energy or do not produce at all.

Ecosphere protection through the implementation of green energy is becoming, especially in recent years, a more stringent issue related with the survival of our Technosphere and Valuesphere (Hofstetter, 1998).

A sustainable project based on the use of renewable energies from wind and sun needs to seriously analyze and describe the essential functions and interrelationships of the individual site factors and to establish acceptable technical solutions and limits of change during and after the start-up of these plants.

\section{Materials and Methods}

Romania has managed rapid introduction of windmill farms to generate on average about $25-30 \%$ of domestic energy needs. Likewise in Italy, where the adoption by the government of the EU Directives on domestic electricity markets 96/92/CE and 2001/77/CE related to "green certificates" has favored, since the early 2000, a progressively increase of the amount of "green" electricity transferred into the national electric grid, the renewable resources energy production is steadily growing.

The system of incentives has positively affected the number and size of installed wind power generators that has grown from small $70 \mathrm{~kW}$ to medium sizes $250-300$ $\mathrm{kW}$ plant (EERR, 2013) and of the Photovoltaic farms that grow up to about $19 \mathrm{GWh}$ of installed capacity in 2012 (EEUP, 2015).

However, some critical technical problems have arisen during testing in location where wind conditions were not adequate have still not be sufficiently faced.

In Romania, wind turbines construction was abruptly halted on the ground that they could have small or long periods, when they do not give energy. In these times when the wind does not blow, the amount of energy that turbines would have to provide needs to be produced otherwise.

For not were built yet and reactors 3 and 4 at Cernavoda (which could operate from small or medium capacity and provide more energy to our country when there is no wind) was sometimes necessary to supplement the energy production with coal.

The two existing reactors in the area generate more energy when needed but can't replace all the energy produced by the wind when necessary. This is a real problem, which must to be solved right now.

A solution to this problem would be the completion and the start-up of reactors 3 and 4 at Cernavoda.

Another sophisticated solution, which would allow even further additional wind energy sources, is to build an exceptionally energetic local plant based on the concept of a symbiotic system. This paper will present one such system.

Hydropower has been used since ancient times for many kinds of watermills or has been used as a renewable energy source to irrigation and to operate various mechanical devices (Sabău, 2015; Sabău and Iovan, 2015).

A known method to produces energy, an electric energy that could supply a progressively higher energy demands, is moving and storing water between reservoirs at different elevations. This method is named pumped-storage.

The excess of the wind generation capacities when energy demand is low could be used to pump water into reservoirs positioned upper, while when the energy demand becomes greater, water is released through a turbine back into a lower positioned reservoir (Fig. 1). 


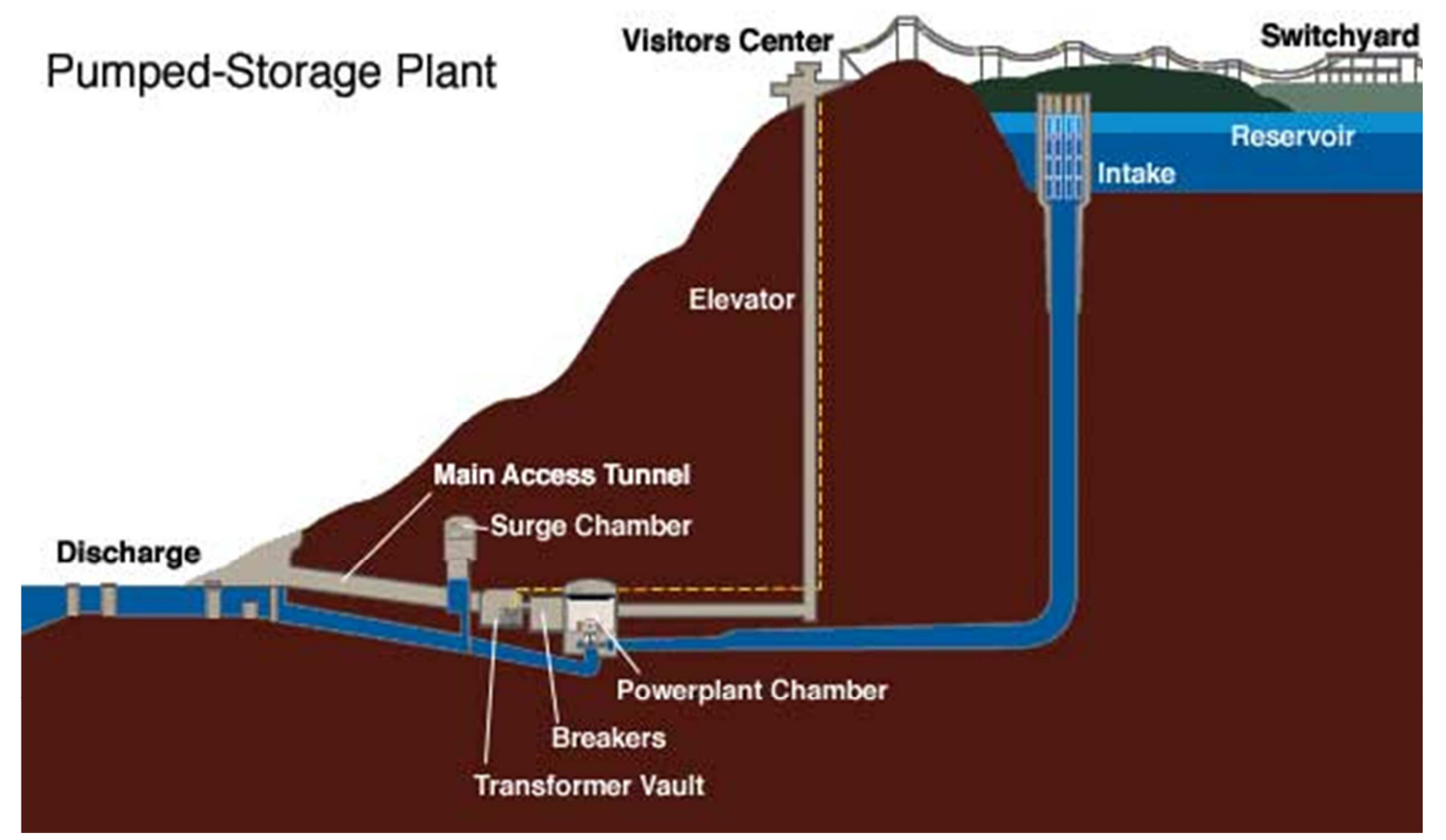

Fig. 1. Diagram of the TVA pumped storage facility at raccoon mountain pumped-storage plant, Source: https://en.wikipedia.org/wiki/Pumped-storage_hydroelectricity\#/media/File:Pumpstor_racoon_mtn.jpg

Such symbiotic systems can be positioned everywhere in any countries, even in any great existing hydropower. But the need for symbiosis with existing windmills requires the construction of such a system even in ROMANIA in Dobrogea area.

It can build such a hydropower plant in that area with the great advantage to be constantly supplied with water pumped even further by the surplus electricity generated by wind (that otherwise would be lost).

For a better understanding of the ideas, we will present below, very briefly, special technical characteristics of a windmill (Dubău, 2015).

Electric power generated by wind is proportional to the cube of the wind speed.

A windmill is set to function optimally for a small or medium wind speed. If the speed of wind in the area increases 10 times for example, one single windmill will produce wind power such as a normal production given from the 1000 windmills (El-Naggar and Erlich, 2016).

Obviously, this surplus energy cannot be picked up by any electric network and is lost. There is thus a large amount of energy produced but not used. If this energy could be used to act the pumps that lift water to a storage energy system, it would solve two problems simultaneously. First, it would use the extra energy produced, which is lost otherwise. Second, it would store energy, that is then used in periods of high consumption, or when the wind stops blowing.

\section{Results and Discussion}

On September 4, 2013, Romania has surpassed the psychological threshold of $2 \mathrm{GW}$ of renewable energy produced by wind, solar and biomass. Thus, given that the total energy production was $7 \mathrm{GW}$, result that the proportion of green energy sources in our country is about one third.

The wind sector produces in Romania the largest amount of renewable energy, with a daily average of 1,900 MW, followed by photovoltaic branch, only 100 MW. On the other hand, the biomass sector came to a halt, the production being constant, only $34 \mathrm{MW}$.

Data released by Transelectrica shows that on 4 September 2013 the wind energy production, representing $27 \%$ of the total, has been leading in the ranking of energy sources, followed by energy from coal, nuclear, hydro and the one based on hydrocarbons.

According to the legal provisions in force, the energy from renewable sources is received with priority in the network and a such as energy production as big as the one recorded in September 4 2013, would have caused difficulties in the national energy system. As such, National Power Control stops delivering networked energy in hydro and coal sector when green energy production is high and population demand is low.

In other words, when wind energy is very high (when strong winds are blowing) energy production on coal and 
hydro are limited and even stopped temporarily. But the inverse problem (when windy force drops and the demand is high from population and industry) is more difficult to solve.

Usually in such situations all hydro and coal plants are utilized at maximum capacity.

A more viable solution would be to introduce into the national power grid yet two nuclear fission reactors. However, an efficient important alternative would be the introduction of hydro energy storage systems, as it has been previously described.

It is estimated that in the Romanian energy system would require investments of several billion Euros to ensure confidence in the system takeovers of a significant amount of intermittent energy.

The system described in presented article would require a much more inexpensive investment for Romanian country.

Compensation schemes currently in use are polluting, difficult to handle and fail to compensate for green energy fluctuations of more than $2 \mathrm{GW}$ (installed power).

The new proposed scheme has the advantage of being able to operate on a longer period (longer periods in that the wind does not blow). If the amount of stored water is higher, or the height of the lifted water is higher, such a system could work for a longer period of time without being refueled. If it want such a system to replace total green energy wind for a much longer period, it will be necessary to build more such schemes.

As a lifeline if it would like to remain driven pumps and on windless period, it is possible, but this time they must to be powered from another source. This source of electrical power could come from existing nuclear plants (which would work then at full capacity) from photovoltaic panels, from a solar farm complementary, or by burning hydrogen extracted from water (through modern methods, with nanocells, to not have big yield losses), (Muthumeenal et al., 2016).

A large hydropower with pumped-storage built somewhere on Danube or on the Danube-Black Sea channel, near the wind farms, could store and give energy for a long period of time (for a week or maybe two) without wind alimentation. For possible windless periods longer than a month would be needed three or four such centers. It would be possible to build such a central solution in floors, with several levels of water lift and storage. Today appeared very large windmills that have an installed power very much improved compared to conventional models.

Instead of a wind national park with 1000-2000 windmills, we may build today a modern wind park with the same power having only 100 windmills, each with an installed capacity much higher than the older models. Wind energy is practically inexhaustible. We use the wind! Capture its energy and transform into electricity or store it as water potential energy.

\section{Conclusion}

A systemic approach, comprising all research and development activities that support the expansion of ecoefficient industrial and social systems fulfilling market and social-cultural constrains, is required to accomplish the challenge for competitiveness and sustainability along with an increasingly dynamic and complex global scientific, industrial and cultural scenarios. Ecosphere protection through the implementation of green energy is becoming a daily technological reality. Especially in recent years, various sources of green energy have been introduced in our Technosphere and Valuesphere. The process, which has began with difficulty but finally resulted in the acceleration and implementation of new green energy technologies, is still impaired by major emerging limitations. The most worldwide experienced difficult obstacle was the unpredictable and fluctuating green energy production. This study proposes some solutions designed to solve this unpleasant aspect of inconstant production of green energy. The basic idea refers to the construction of specially designed hydroelectric plant that represents a true energy buffer. A hydroelectric old (adequately equipped) or a new one built according to this principle, can become a true buffer energetic, able to take energy generated by the turbines at full capacity (energy otherwise lost by unable to be stored or taken over by the national network) and a national system restore when green energy sources produce shorten.

The wind farms are reliable, sustainable economically, friendly and technologically affordable.

Installing wind farms is obvious only in areas where winds blow often and hard. Even in these areas, however, there may occur that sometimes wind force reduces or stops for longer times. This occurrence should introduce the use of wind energy.

Obviously, in these times, the energy must be supplied by other sources. One can use more wind farms built in totally different areas, so if one of them is no longer in the wind, in exchange for the other to have continuous activity. It can use in the same area, wind energy parks combined with solar farms.

One still can use the fission nuclear power, accepting it as a necessary evil.

But a smart way to build green energy areas is to put a wind farm together with a storage hydropower.

The main advantage of the proposed solution is that it would use only additional green energy (otherwise lost) as buffer energy, through water temporarily kept at a higher elevation increasing its potential energy, which represents a valuable example of Ecosphere protection as a symbiotic intersection of Technosphere and Valuesphere: No oil, no coal (no hydrocarbons) in use, no pollution while producing economic advantages. 


\section{Acknowledgement}

This text was acknowledged and appreciated by Dr. Veturia CHIROIU Honorific member of Technical Sciences Academy of Romania (ASTR) PhD supervisor in Mechanical Engineering, S. P. Kozaitis Professor and Department Head Electrical and Computer Engineering Florida Institute of Technology, Muftah $\mathrm{H}$. El-Naas PhD MCIC FICCE QAFCO Chair Professor in Chemical Process Engineering Gas Processing Center College of Engineering Qatar University, Professor Guanying Chen Harbin Institute of Technology and SUNY Buffalo China, (Ms.) Shweta Agarwala Senior Research Scientist at Singapore Center for 3D Printing Nanyang Technological University Singapore, whom we thanks and in this way.

\section{Author's Contributions}

All the authors contributed equally to prepare, develop and carry out this manuscript.

\section{Ethics}

This article is original. Authors declare that are not ethical issues that may arise after the publication of this manuscript.

\section{References}

Apicella, A., D. Ianniello and R. Aversa, 2010. Application of nanostructured smart materials in sustainable buildings. Int. J. Sustainable Manufactur., 2: 66-79. DOI: 10.1504/IJSM.2010.031620

Barone, G., A. Buonomano, C. Forzano and A. Palombo, 2015. WLHP systems in commercial buildings: A case study analysis based on a dynamic simulation approach. AJEAS, 9: 659-668. DOI: 10.3844 /ajeassp.2016.659.668

Barrett, G.W. and E.P. Odum, 2000. The twenty-first century: The world at carrying capacity. BioScience, 50: 363-368. DOI: 10.1641/00063568(2000)050[0363:TTFCTW]2.3.CO;2

Colvin, L., H. Leonard, N. de Klerk, M. Davis and L. Weaving et al., 2004. Refining the phenotype of common mutations in Rett syndrome. J. Med. Genet., 41: 25-30. DOI: 10.1136/jmg.2003.011130

de Silva, N., I.S. Jawahir, O.W. Jr Dillon and M. Russell, 2009. A new comprehensive methodology for the evaluation of product sustainability at the design and development stage of consumer electronic products. Int. J. Sustainable Manufactur., 1: 251-264. DOI: 10.1504/IJSM.2009.023973

Dubău, C., 2015. Vertical axis wind turbine power rating. Analele Universității Oradea Fascicula Protecția Mediului., 24: 313-316.
El-Naggar, A. and I. Erlich, 2016. Analysis of fault current contribution of Doubly-Fed Induction Generator Wind Turbines during unbalanced grid faults. Renewable Energy, 91: 137-146. DOI: $10.1016 /$ j.renene.2016.01.045

EEUP, 2015. Study concerning the state of the art of the renewable energy sector in the Adriatic-Ionian coastal-marine areas. Enercoast EU Project.

EERR, 2013. The state of renewable energies in Europe. EurObserv'ER Report.

Hofstetter, P., 1998. Perspectives in Life Cycle Impact Assessment: A Structured Approach to Combine Models of the Technosphere, Ecosphere and Valuesphere. 1st Edn., Springer Science and Business Media, ISBN-10: 079238377X, pp: 484.

Hofstetter, P., T. Baumgartner and R.W. Scholz, 2000. Modelling the valuesphere and the ecosphere: Integrating the decision makers' perspectives into LCA. Int. J. LCA, 5: 161-161. DOI: 10.1007/BF02978618

Kaebernick, H., M. Anityasari and S. Kara, 2002. A technical and economic model for End-of-Life (EOL) options of industrial products. Int. J. Environ. Sustainable Develop., 1: 171-183. DOI: 10.1504/IJESD.2002.000727

Mohsin, I., 2015. An overview of Energy Loss Reduction (ELR) software used in Pakistan by WAPDA for calculating transformer overloading, line losses and energy losses. AJEAS, 9: 442-448. DOI: 10.3844/ajeassp.2016.442.448

Muthumeenal, A., S.S. Pethaiah and A. Nagendran, 2016. Investigation of SPES as PEM for hydrogen production through electrochemical reforming of aqueous methanol. Renewable Energy, 91: 75-82. DOI: 10.1016/j.renene.2016.01.042

Petrescu, F.I. and R.V. Petrescu, 2011. Perspective Energetice Globale. 1st Edn., CreateSpace Independent Publishing Platform, ISBN-10: 146813082X, pp: 80.

Petrescu, F.I. and R.V. Petrescu, 2012. Green Energy. 1st Edn., BoD-Books on Demand, Norderstedt, ISBN-10: 3848223635, pp: 116.

Petrescu, F.I. and R.V. Petrescu, 2014. Nuclear green energy. IJAP, 10: 3-14.

Pineda, S. and A. Bock, 2016. Renewable-based generation expansion under a green certificate market. Renewable Energy, 91: 53-63. DOI: 10.1016/j.renene.2015.12.061

Pisello, A.L., G. Pignatta, C. Piselli, V.L. Castaldo and F. Cotana, 2015 Investigating the dynamic thermal behavior of building envelope in summer conditions by means of in-field continuous monitoring. AJEAS, 9: 505-519. DOI: $10.3844 /$ ajeassp.2016.505.519 
Ramenah, H. and C. Tanougast, 2016. Reliably model of microwind power energy output under real conditions in France suburban area. Renewable Energy, 91: 1-10.

DOI: $10.1016 /$ j.renene.2015.11.019

Sabău, N.C., 2015. Energy production in hydropowers and electric thermal power plants from the perspective of european community legislation. Analele Universității Oradea Fascicula Protecția Mediului, 24: 235-248.

DOI: 10.13140/RG.2.1.2630.1528
Sabău, N.C. and I.C. Iovan, 2015. Some aspects of determination galbena valley hydropower characteristics, using method for determining the flow from the possible locations of small hydropower (MHC). Analele Universității Oradea Fascicula Protecția Mediului, 25: 267-278.

Sepúlveda, J.A.M., 2015. Outlook of municipal solid waste in bogota (Colombia). AJEAS, 9: 477-483. DOI: $10.3844 /$ ajeassp.2016.477.483 